\title{
PERANCANGAN APLIKASI DATA KARYAWAN BERBASIS ANDROID
}

\author{
Iwan Kurniawan \\ Program Studi Informatika, Fakultas Teknik dan Ilmu Komputer, Universitas Indraprasta PGRI \\ Jalan Raya Tengah No 80, Kelurahan Gedong, Pasar Rebo, Jakarta Timur \\ ircomputer2012@gmail.com
}

\begin{abstract}
Abstrak
Data dan informasi adalah aset penting sebuah perusahaan. Oleh karena itu, perusahaan selalu mencari alternatif untuk mengatasi permasalahan data dan informasi. Tujuan dari pengembangan aplikasi ini adalah untuk memberikan informasi tentang data karyawan yang bekerja di sebuah perusahaan yang berisi profil karyawan, data karyawan, data pekerjaan dan data tunjangan yang terdapat di perusahaan tersebut. Pengembangan aplikasi ini menggunakan metode extreme programming yang memiliki fase-fase seperti planning, design, coding, dan testing. Aplikasi ini dibuat menggunakan software Android Studio. Hasil dari pengembangan aplikasi ini adalah suatu aplikasi yang berisi informasi mengenai data karyawan dan data pekerjaan yang terdapat dalam sebuah perusahaan.
\end{abstract}

Kata Kunci: Data, Informasi, Karyawan, Extreme programming

\begin{abstract}
Data and information are important assets of a company. Therefore, the company is always looking for alternatives to solve data and information problems. The purpose of the development of this application is to provide information about employee data working in a company that contains employee profiles, employee data, employment data and benefits data contained in the company. The development of this application uses extreme programming methods that have phases such as planning, design, coding, and testing. This app is created using Android Studio software. The result of the development of this application is an application that contains information about employee data and employment data contained in a company.
\end{abstract}

Keyword: Data, Information, Employees, Extreme programming

\section{PENDAHULUAN}

Berkembangnya kebutuhan Good Corporate Governance (GCG) atau Tata Kelola Perusahaan yang Baik untuk mengarahkan dan mengelola kegiatan suatu perusahaan mempunyai pengaruh besar dalam menentukan sasaran usaha maupun dalam upaya mencapai sasaran tersebut. Salah satu aspek yang harus dipenuhi oleh perusahaan adalah kejelasan fungsi, struktur, sistem dan pertanggungjawaban organ perusahaan sehingga pengelolaan perusahaan terlaksana secara efektif. Untuk itu, salah satu kegiatan penting yang harus perusahaan terapkan adalah pengelolaan data karyawan seperti manajemen biodata karyawan, tugas dan fungsi seorang karyawan sehingga kejelasan sistem dan pertanggungjawaban organ perusahaan dapat terkelola dengan benar.

Berdasarkan latar belakang masalah tersebut maka permasalahan yang akan dikaji dalam penelitian ini dapat dirumuskan sebagai berikut yaitu bagaimana merancang dan membangun perangkat lunak berbasis android yang dapat digunakan oleh perusahaan untuk melihat sistem informasi karyawan, bagaimana menerapkan metode extreme programming dalam pengembangan perangkat lunak pada perusahaan.

Adapun penelitian ini bertujuan untuk merancang dan membangun aplikasi data karyawan berbasis android yang dapat digunakan semua perusahaan berskala nasional. Aplikasi Data Karyawan berbasis Android ini diharapkan dapat membantu seluruh karyawan dan pihak manajemen perusahaan dalam melihat sistem informasi karyawan. Perancangan adalah proses pengembangan spesifikasi baru berdasarkan rekomendasi hasil analisis system (Subhan, 2012). Aplikasi merupakan program yang berisikan perintah-perintah untuk melakukan pengolahan data (Jogiyanto, 2010). Aplikasi (application) adalah software yang dibuat oleh suatu perusahaan komputer untuk mengerjakan tugas-tugas tertentu, misalnya Microsoft word, dan microsoft excel 
(Dhanta, 2009). Sejak rilis perdana Android pada tahun 2007 hingga tahun 2017, Android sudah mengeluarkan banyak versi (Budi Setyo, 2018).

Perbedaan yang mendasar pada penelitan yang peneliti kerjakan adalah pada tampilan menu utama dimana peneliti menggunakan 4(empat) fragmen utama dimana tiap-tiap fragmen terdiri dari ikon atau menu yang dapat dipilih berdasarkan kategori. Contoh didalam fragmen home terdiri dari ikon profil saya, data karyawan,data pekerjaan dan data tunjangan dimana tiap-tiap ikon dapat dipilih untuk melihat isi data yang terdapat di halaman selanjutnya. Sedangkan penelitian relevan yang saya pelajari hanya terdapat 1 (satu) fragmen dimana didalam fragmen tersebut terdapat tombol untuk membuka halaman selanjutnya. Artinya jika hanya 1(satu) fragmen utama tidak bisa membuat sub-sub kategori dan tampilannya pun jadi sangat terbatas untuk membuat sub kategori dari pilihan menu utama.

\section{PENELITIAN RELEVAN}

Penelitian yang digunakan sebagai acuan dalam penelitian ini adalah sebagai berikut: Penelitian oleh Irsyad Dwi Cahyono (2018) dengan judul Perancangan Aplikasi Kegiatan Pola Hidup Sehat Berbasis Android. Hasil Penelitian tersebut adalah aplikasi yang bertujuan untuk memberikan informasi tentang pola hidup sehat dalam bentuk sebuah aplikasi berbasis android dan berisi reminder atau pengingat dalam penyampaian informasi ini. Penelitian oleh Aji Widodo (2018) dengan judul Perancangan Edukasi Pengenalan Budaya Indonesia Berbasis Android. Hasil dari penelitian tersebut adalah aplikasi pengenalan budaya Indonesia agar dapat meningkatkan minat anak dalam mempelajari atau mengenal keanekaragaman budaya Indonesia yang dapat dipasang pada smartphone bersistem operasi Android.

\section{METODE PENELITIAN}

\section{Diagram Alir}

Peneliti menjelaskan mengenai metodologi yang digunakan dalam penelitian ini, dimana hasil akhirnya adalah berupa aplikasi data karyawan berbasis android. Berikut adalah diagram alir dari penelitian ini.

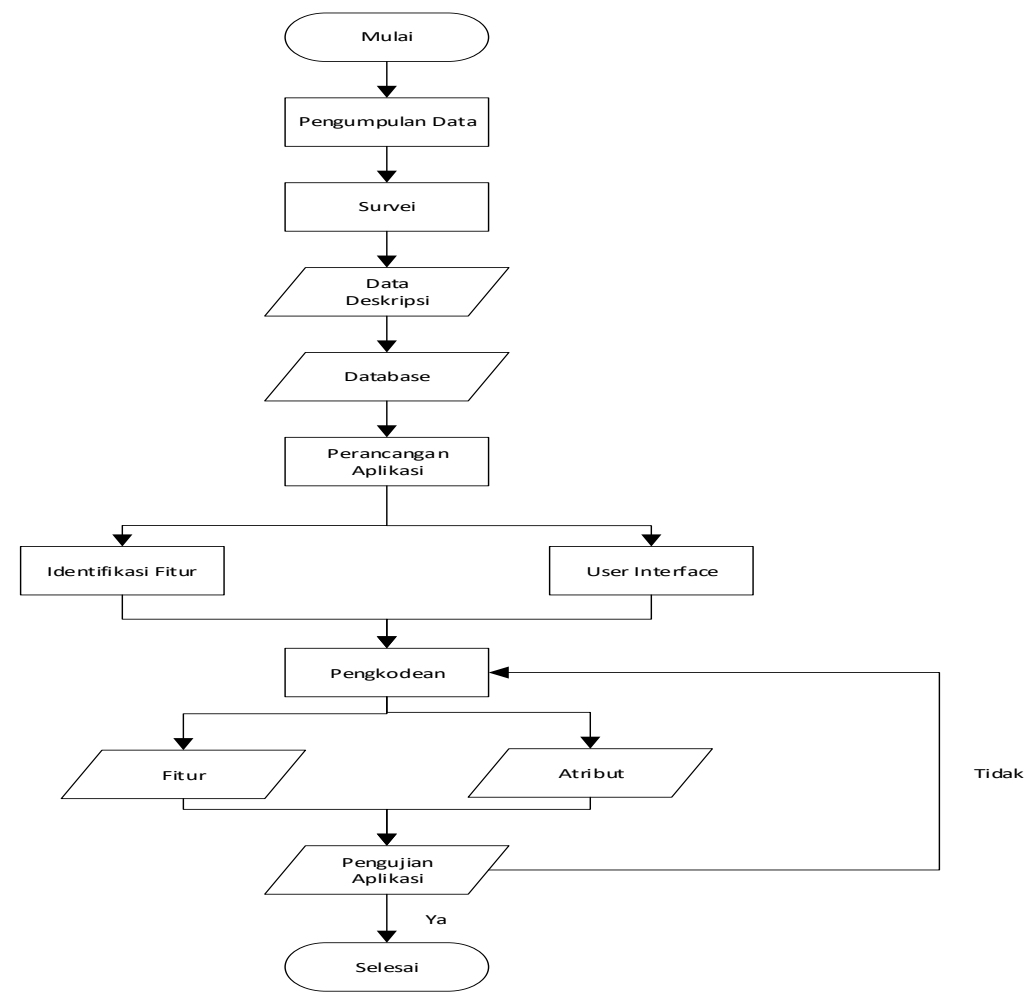

Gambar 1. Diagram Alir 


\section{Teknik Pengumpulan Data}

Metode penelitian menurut adalah penyaluran rasa ingin tahu manusia terhadap sesuatu masalah dengan perakuan tertentu (seperti memaksa, menghasut, menelaah dan mempelajari secara cermat serta sungguh-sungguh)", sehingga diperoleh sesuatu (seperti mencapai kebenaran, dan sebagainya (Harahap, 2012). Metode penelitian yang dilakukan adalah grounded research (penelitian berdasarkan fakta). Penelitian yang dilakukan bersifat evaluative. Peneliti hanya mencari dan mengumpulkan data, untuk melakukan klasifikasi terhadap data tersebut, mengolah, dan menganalisa data, membangun hipotesis menjadi teori. Dalam pengumpulan data, peneliti menggunakan beberapa teknik pengumpulan data dalam penelitian antara lain studi kepustakaan dengan cara pengumpulan data dan informasi dari kutipan-kutipan buku-buku serta hasil laporan dan bahan lainnya yang berkaitan dengan penelitian ini, observasi dengan cara melakukan pengamatan secara langsung terhadap objek penelitian, instrumen penelitian dengan cara pengumpulan data dengan perekam gambar seperti kamera digital yang berguna sebagai alat bantu pada saat observasi

\section{Langkah-langkah Pengembangan Sistem}

Penelitian dilakukan bedasarkan metode pengembangan sistem yang dipih yaitu Extreme Programming (XP). Tahap-tahap yang dilakukan dalam perancangan Apikasi Data Karyawan ini adalah sebagai berikut:

\section{Planning}

Dalam tahap ini dikumpulkan kebutuhan awal user atau dalam $X P$ disebut $u s e r$ stories.Hal ini dibutuhkan agar pengembang mengerti bisnis konten, kebutuhan output sistem, dan fitur utama dari software yang dikembangkan.

2. Design

Mendesain struktur data, arsitektur perangkat lunak, rincian prosedural, dan karakteristik antar muka.

3. Coding

Pada tahap ini dibangun aplikasi yang menjadi objek penelitian. Aplikasi dibangun berdasarkan desain yang telah dibuat pada tahap sebelumnya. Dalam pembangunan aplikasi ini menggunakan Bahasa pemrograman Java, serta XML untuk tampilan pada Android. Refactoring adalah proses mengubah sistem perangkat lunak sedemikian rupa dengan tidak mengubah eksternal kode dalam memperbaiki struktur internalnya. Hal ini dilakukan untuk meminimalkan kemungkinan adanya bug.

4. Testing

Pada tahap ini aplikasi yang telah dibangun diuji apakah kebutuhan awal user atau user stories sudah dipenuhi dan apabila terpenuhi aplikasi siap dirilis.

\section{HASIL DAN PEMBAHASAN \\ Struktur Navigasi Aplikasi Data Karyawan}

Perancangan aplikasi data karyawan berbasis merupakan bentuk implementasi menggunakan device android yang diperuntukkan untuk $H R D$ dan karyawan dalam masa kerja untuk memperoleh informasi dasar seperti biodata karyawan, masa kerja karyawan, dan informasi lainnya yang berhubungan dengan perusahaan tempat karyawan itu bekerja. Aplikasi dibangun menggunakan Android Studio, Software SDK dan JDK, karena software tersebut memang biasa digunakan untuk membuat objek/benda dalam computer dan bersifat Open Source atau terbuka untuk dikembangkan. 


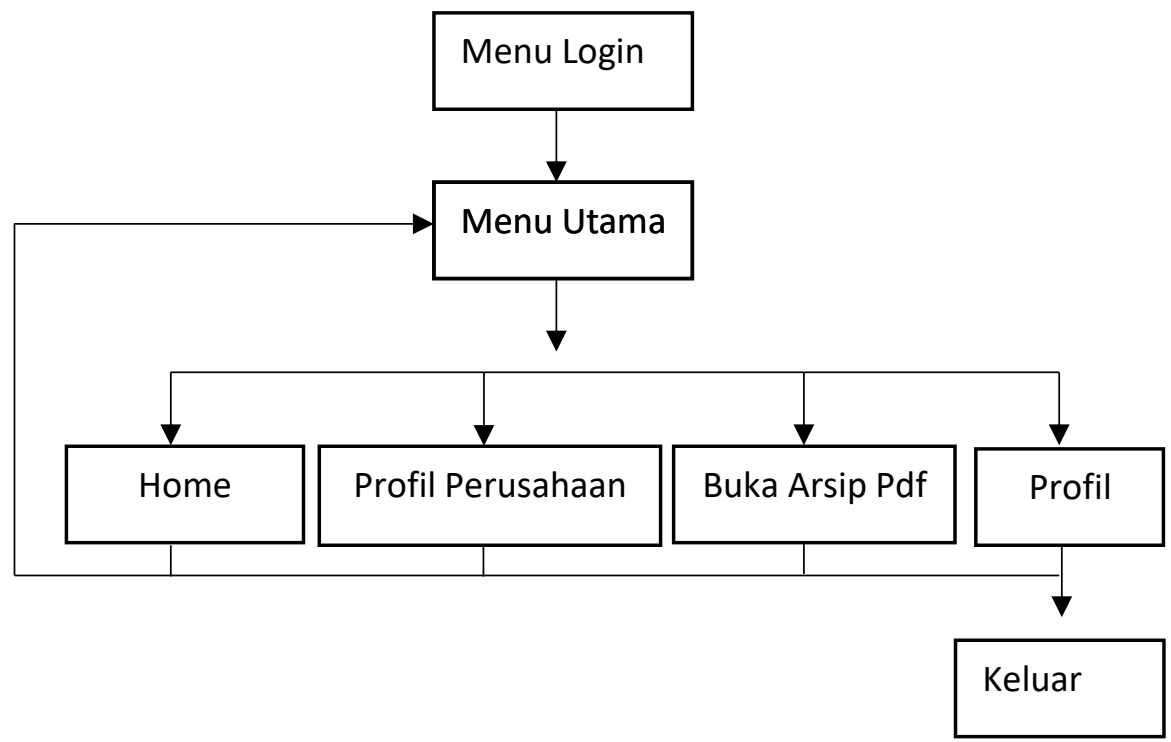

Gambar 2. Struktur Navigasi

\section{Tampilan Aplikasi}

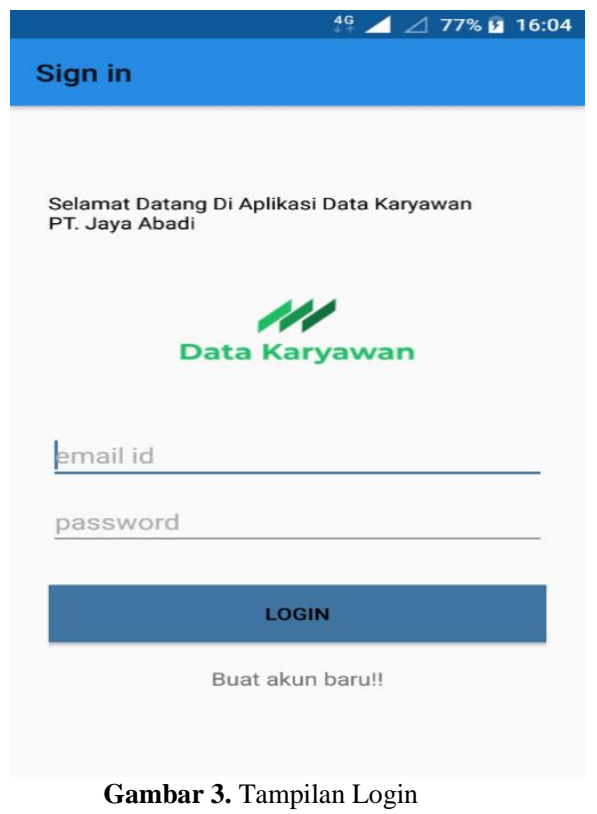

Tampilan menu login menggunakan menu login dengan authentikasi email. 


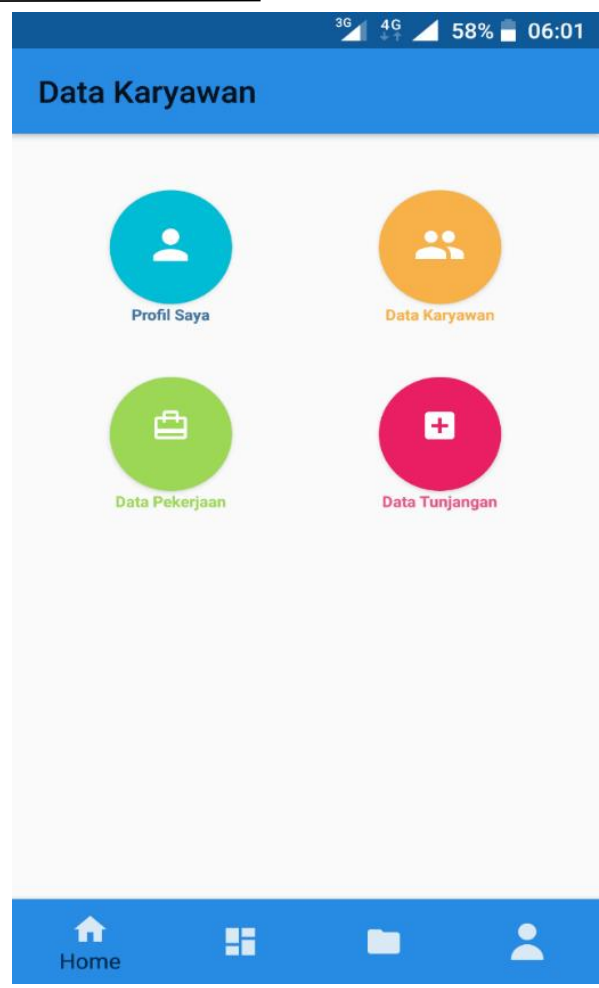

Gambar 4. Tampilan Menu Utama

Tampilan menu utama menggunakan menu navigasi dengan style bottom navigation dan berisi 4 layout / fragment utama yaitu

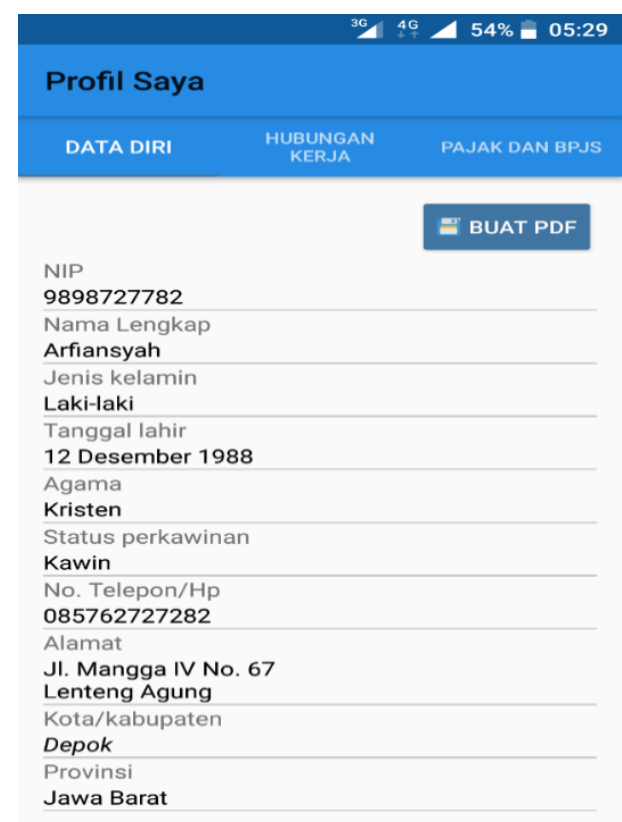

Gambar 5. Tampilan Menu Profil Saya

Tampilan menu profil saya dimana di listrview activity ini menggunakan 3 (tiga) tab layout dan menampilkan data diri pengguna, hubungan kerja dengan perusahaan, dan nomor kepesertaan pajak dan bpjs. 


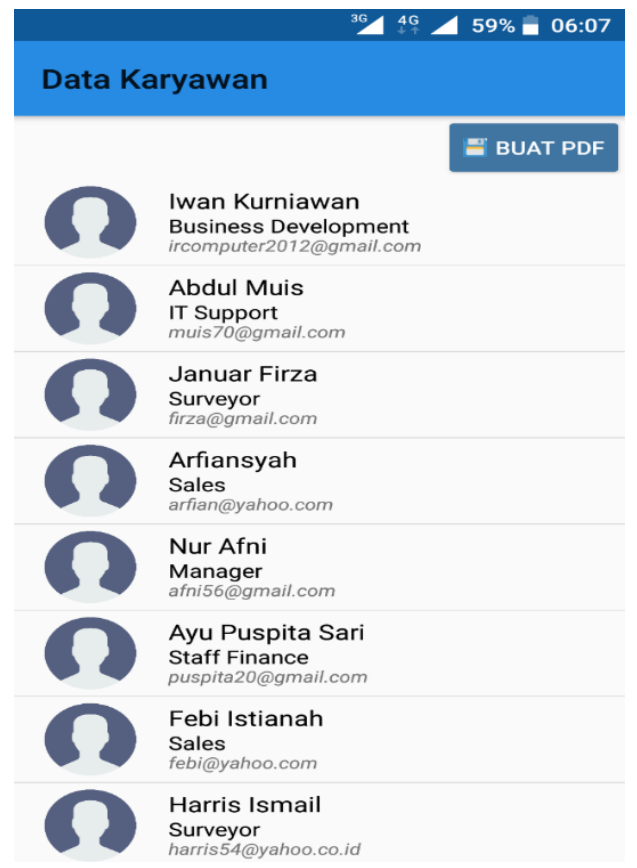

Gambar 6. Tampilan Menu Data Karyawan

Tampilan menu data karyawan yang berisi tentang nama,jabatan dan email karyawan.

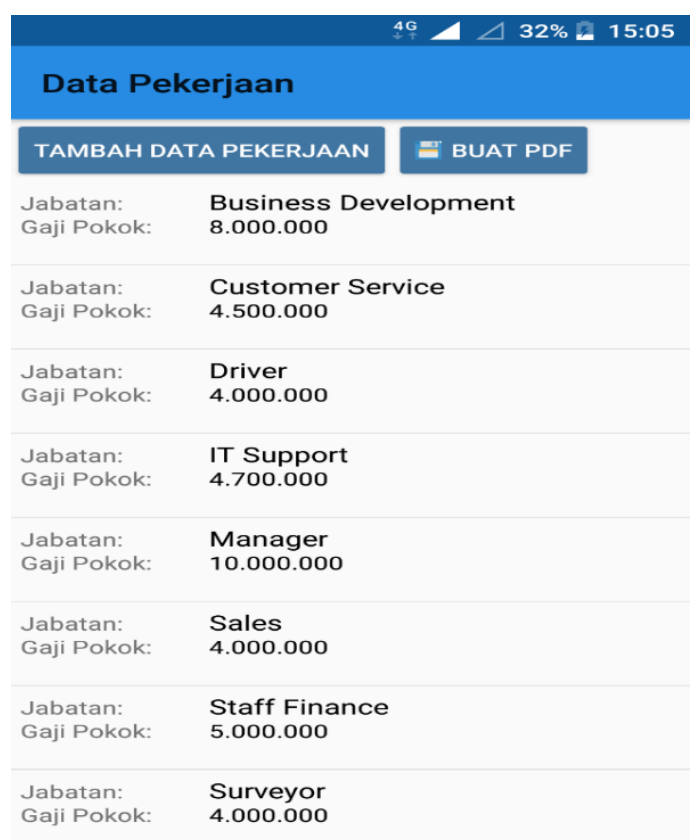

Gambar 7. Tampilan Menu Data Pekerjaan

Tampilan menu data pekerjaan dimana peneliti menggunakan listview activity untuk menampilkan data pekerjaan berupa jabatan dan gaji pokok. 


\begin{tabular}{|c|c|}
\hline \multicolumn{2}{|l|}{ Data tunjangan } \\
\hline & E BUAT PDF \\
\hline $\begin{array}{l}\text { Jabatan : } \\
\text { Business Development }\end{array}$ & \\
\hline $\begin{array}{l}\text { Tunjangan keluarga : } \\
\text { 1.000.000 }\end{array}$ & \\
\hline $\begin{array}{l}\text { Tunjangan kesehatan : } \\
\text { 500.000 }\end{array}$ & \\
\hline $\begin{array}{l}\text { Tunjangan transportasi : } \\
500.000\end{array}$ & \\
\hline $\begin{array}{l}\text { Tunjangan pendidikan : } \\
100.000\end{array}$ & \\
\hline $\begin{array}{l}\text { Jabatan: } \\
\text { Customer Service }\end{array}$ & \\
\hline $\begin{array}{l}\text { Tunjangan keluarga : } \\
500.000\end{array}$ & \\
\hline $\begin{array}{l}\text { Tunjangan kesehatan : } \\
\mathbf{3 0 0 . 0 0 0}\end{array}$ & \\
\hline $\begin{array}{l}\text { Tunjangan transportasi : } \\
\mathbf{3 0 0 . 0 0 0}\end{array}$ & \\
\hline $\begin{array}{l}\text { Tunjangan pendidikan : } \\
\mathbf{1 0 0 . 0 0 0}\end{array}$ & \\
\hline $\begin{array}{l}\text { Jabatan : } \\
\text { Driver }\end{array}$ & \\
\hline $\begin{array}{l}\text { Tunjangan keluarga : } \\
\mathbf{5 0 0 . 0 0 0}\end{array}$ & \\
\hline
\end{tabular}

Gambar 8. Tampilan Menu Data Tunjangan

Tampilan menu data tunjangan yang menampilkan tunjangan keluarga, tunjangan kesehatan, tunjangan transportasi, dan tunjangan pendidikan.

Data Karyawan

PT. JAYA ABADI

Jl.Raya Perjuangan No.1, Kebon Jeruk, Jakarta Barat, Kode Pos 11530 Indonesia

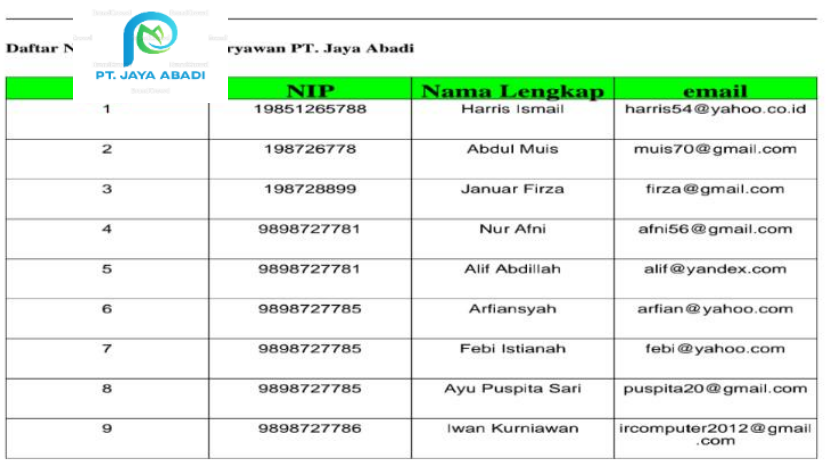

Jakararta, Kamis s September 2019
ITD Manager

Gambar 9. Tampilan Menu Laporan Data Karyawan 


\section{Pembahasan Hasil Uji Coba}

Terdapat juga beberapa hasil percobaan di handphone android jenis lainnya, dibawah ini adalah tabel hasil data percobaan aplikasi data karyawan berbasis android.

Tabel 1.

Uji coba program dengan contoh data

\begin{tabular}{|c|c|c|c|c|c|c|c|}
\hline No. & Merk & Type & $\begin{array}{l}\text { Versi } \\
\text { OS }\end{array}$ & Instalasi & $\begin{array}{l}\text { Kualitas } \\
\text { Gambar }\end{array}$ & $\begin{array}{l}\text { Tampilan } \\
\text { Layout }\end{array}$ & Error \\
\hline 1. & Asus & Zenfone Go & 5.1 .1 & Berhasil & Baik & Baik & Tidak Ada \\
\hline 2. & LG & X Power K220 & 6.0 .1 & Berhasil & Baik & Baik & Tidak Ada \\
\hline 3. & Xiaomi & Redmi 5a & 7.1.1. & Berhasil & $\begin{array}{l}\text { Sangat } \\
\text { Baik }\end{array}$ & Sangat Baik & Tidak Ada \\
\hline 4. & Nokia & Nokia 6 & 8.0 .0 & Berhasil & $\begin{array}{l}\text { Sangat } \\
\text { Baik }\end{array}$ & Sangat Baik & Tidak Ada \\
\hline 5. & Oppo & F9 & 8.1 .0 & Berhasil & $\begin{array}{l}\text { Sangat } \\
\text { Baik }\end{array}$ & Sangat Baik & Tidak Ada \\
\hline 6. & Samsung & A8 2018 & 9.0 .0 & Berhasil & $\begin{array}{l}\text { Sangat } \\
\text { Baik }\end{array}$ & Sangat Baik & Tidak Ada \\
\hline
\end{tabular}

Setelah peneliti melakukan pengujian terhadap aplikasi data karyawan berbasis android pada smartphone diatas, aplikasi dapat diinstal dan digunakan dari 6 smartphone tersebut, dan aplikasi dapat berjalan lancar dan cepat.

\section{SIMPULAN}

Dalam pembuatan Aplikasi Data Karyawan Berbasis Android ini diharapkan dapat memberikan kemudahan bagi karyawan dalam mendapatkan informasi yang berkaitan dengan perusahaan seperti tanggal mulai bekerja, informasi kepesertaan asuransi kesehatan maupun ketenagakerjaan serta informasi terkini dengan perkembangan yang sedang terjadi di perusahaan maupun rencana mendatang yang akan dilakukan perusahaan.

\section{DAFTAR PUSTAKA}

Budi Setyo, H. (2018). Memanfaatkan Aplikasi Pendukung Android pada Sistem Operasi Windows. Yogyakarta: C.V. Andi.

Dhanta, R. (2009). Pengantar Ilmu Komputer. Surabaya: Indah.

Harahap, N. S. (2012). Pemrograman Aplikasi Mobile Smartphone dan Tablet PC Berbasis Android. Bandung: Informatika.

Jogiyanto, H. (2010). Analisis dan Desain Sistem Informasi. Yogyakarta: C.V. Andi.

Subhan, M. (2012). Analisa Perancangan Sistem. Jakarta: Lentera Ilmu Cendikia. 